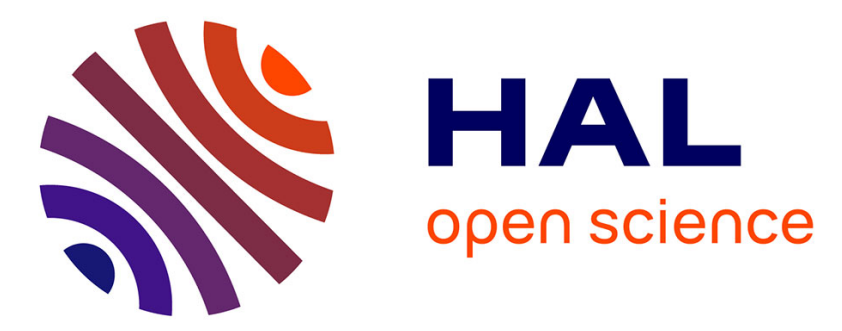

\title{
Local miscommunications between glomerular cells as potential therapeutic targets for crescentic glomerulonephritides
}

Carole Hénique, Olivia Lenoir, Alexandre Karras, Pierre-Louis Tharaux

\section{To cite this version:}

Carole Hénique, Olivia Lenoir, Alexandre Karras, Pierre-Louis Tharaux. Local miscommunications between glomerular cells as potential therapeutic targets for crescentic glomerulonephritides. Néphrologie \& Thérapeutique, 2019, 15, pp.S1 - S5. 10.1016/j.nephro.2019.03.006 . hal-03485068

\section{HAL Id: hal-03485068 \\ https://hal.science/hal-03485068}

Submitted on 20 Dec 2021

HAL is a multi-disciplinary open access archive for the deposit and dissemination of scientific research documents, whether they are published or not. The documents may come from teaching and research institutions in France or abroad, or from public or private research centers.
L'archive ouverte pluridisciplinaire HAL, est destinée au dépôt et à la diffusion de documents scientifiques de niveau recherche, publiés ou non, émanant des établissements d'enseignement et de recherche français ou étrangers, des laboratoires publics ou privés.

\section{(c) (1) $\$$}

Distributed under a Creative Commons Attribution - NonCommercial| 4.0 International 
Dochead: Vascularitides

\section{Local miscommunications between glomerular cells as potential therapeutic targets for crescentic glomerulonephritides}

Perturbations des communications cellulaires glomérulaires comme cibles thérapeutiques potentielles

Carole Hénique $^{\text {a,b,c,d, }}$, Olivia Lenoir ${ }^{\text {a,b }}$, Alexandre Karras ${ }^{a, b, e}$, Pierre-Louis Tharaux ${ }^{a, b}$

${ }^{a}$ Inserm, Paris Cardiovascular Centre (Parcc), 56 rue Leblanc, 75015 Paris, France

${ }^{\text {b }}$ Université Paris Descartes, Sorbonne Paris Cité, 12, rue de l'École-de-Médecine, 75006 Paris, France ${ }^{c}$ Inserm, équipe 21, U955 institut Mondor de recherche biomédicale, 8 rue du Général-Sarrail, 94010 Créteil cedex

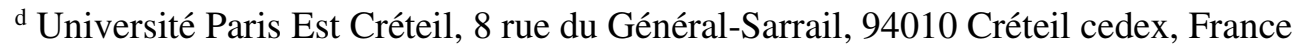

e Renal Division, hôpital européen Georges-Pompidou, Assistance publique-hôpitaux de Paris, 20 rue Leblanc, 75015 Paris, France.

*Corresponding author; e-mail: pierre-louis.tharaux@inserm.fr 


\section{Summary}

Necrotizing and crescentic rapidly progressive glomerulonephritis or crescentic glomerulonephritis is one of the severest forms of acquired glomerular diseases with significant mortality. Risk of end-stage renal failure at 5 years is near $30 \%$, with a number of patients developing chronic kidney disease.

Currently, rapidly progressive glomerulonephritis are treated with broad-spectrum immunosuppression inducing remission of the immune injury in the majority of patients. However, treatment is associated with significant side effects and by the time remission is achieved the majority of patients have developed renal tissue damage and significant impairment of their kidney function with a steep slope of deterioration within the first weeks following initiation of immunosuppression. It is therefore important to develop complementary strategies that would be immediately active on the common process of destructive epithelial processes. We have worked to identify the major cellular pathways contributing to glomerular destruction in this context by a systematic comparison of patient tissues and experimental models. Our studies demonstrate the pivotal role of local intra- and intercellular communications in orchestrating the global glomerular tolerance to a severe rapidly progressive glomerulonephritis model with excellent anatomoclinical correlative expressions in kidney biopsies of individuals diagnosed with rapidly progressive glomerulonephritis, irrespectively of the causal immune disorder. We hope that such approaches deciphering mechanisms of cellular adaptation that underlie kidney damage control in response to vasculitides, integrating both stress and damage responses, will delineate novel complementary therapies.

\section{Keywords}

glomerulonephritis, vasculitis, podocyte, signaling, drug target validation, miRNA

\section{Résumé}

La glomérulonéphrite nécrosante rapidement progressive à croissant est l'une des formes de maladies glomérulaires acquises les plus graves avec une mortalité significative. Le risque d'insuffisance rénale au stade terminal avoisine les $30 \%$ à 5 ans, la majorité des patients développant une insuffisance rénale chronique. Actuellement, les glomérulonéphrites nécrosantes rapidement progressives sont traitées avec une immunosuppression à large spectre induisant une rémission chez la majorité des patients. Cependant, le traitement est associé à des effets secondaires significatifs et au moment de la rémission, la majorité des patients ont développé des lésions rénales sévères avec une perte significative de leur fonction rénale dont la pente de détérioration est maximale au cours des premières semaines malgré l'initiation urgente des immunosuppresseurs. Il importe donc de développer des stratégies complémentaires immédiatement actives sur le processus commun de formation du croissant épithélial destructeur des glomérules. Nous avons travaillé à identifier les voies cellulaires majeures de la destruction glomérulaire dans ce contexte par une comparaison systématique des tissus des patients et de modèles expérimentaux. Nos études démontrent le rôle central de communications intra- et 
intercellulaires locales dans l'orchestration de la perte de tolérance glomérulaire à un modèle de glomérulonéphrite nécrosante rapidement progressive sévère avec des corrélations anatomocliniques excellentes dans les biopsies rénales de patients, indépendamment du trouble immunitaire causal. Nous espérons que de telles approches, qui décrypteront les mécanismes d'adaptation cellulaire qui sous-tendent le contrôle de la tolérance glomérulaire aux vascularites et intègrent à la fois les réponses au stress et les réactions aux lésions, permettront de définir de nouvelles thérapies complémentaires.

\section{Mots clés}

glomérulonéphrites, vascularites, podocyte, transduction du signal, thérapie, micro-ARN

\section{Introduction}

Necrotizing and crescentic rapidly progressive glomerulonephritis or crescentic glomerulonephritis is a life-threatening disease that destroys kidneys over a period of days to weeks. Various unrelated immune disorders promote crescentic glomerulonephritis, which represents one of the few diagnostic and therapeutic emergencies in nephrology. Crescentic glomerulonephritis is typically associated with the syndrome of rapidly progressive glomerulonephritis, which can occur in most forms of inflammatory glomerular injury, including antineutrophil cytoplasmic antibody (ANCA)-associated vasculitis, antiglomerular basement membrane antibody disease, immune-complex-mediated diseases such as postinfectious glomerulonephritis, Henoch-Schönlein purpura, IgA nephropathy or lupus nephritis.

Crescentic glomerulonephritisis one of the severest forms of acquired glomerular diseases with a mortality of approximately $25 \%$ at year 5 . Risk of end-stage renal failure at 5 years is near $30 \%$, with a number of patients developing chronic kidney disease (1). Currently, crescentic glomerulonephritisis treated with broad-spectrum immunosuppression inducing remission of the immune injury in the majority of patients $(2,3)$. However, treatment is associated with significant side effects and by the time remission is achieved the majority of patients have developed renal tissue damage and significant impairment of their kidney function with a steep slope of deterioration within the first 6 months (3-8). Main causes of death within the first year are infectious complications of immunosuppressive therapy and active vasculitis. After the first year, the major causes of death are cardiovascular disease, malignancies, and infections (9). Thus, although the recent decades have seen a marked improvement of the immunosuppressive regiments with a better therapeutic index and improved survival of patients with crescentic glomerulonephritis, in particular with ANCA-associated vasculitis, the disease prognosis is still severe. Therefore, a swifter and more efficient halt of the glomerular injurious process is an urgent medical need in this situation. 
Each glomerulus in the kidney is composed of a network of capillary loops lined by a fenestrated endothelium and covered by interdigitating foot processes of podocytes. Both cell types produce an intervening glomerular basement membrane. There are four resident cell types in the glomerulus: endothelial cells, mesangial cells, parietal epithelial cells of the Bowman's capsule, and podocytes. Podocytes are pericyte-like cells with a complex cellular organization consisting of a cell body, major processes, and foot processes. Podocytes are capable of modulating hydrostatic ultrafiltration of blood plasma and contribute to a molecular sieve that allows for the passage of solutes but retains vital proteins. Furthermore, they secrete soluble factors to regulate other glomerular cell types and facilitate the synthesis and maintenance of the glomerular basement membrane. Impairment of any of these functions following podocyte injury results in proteinuria and, possibly, renal failure. Podocytes are highly specialized cells with limited division capability in adults, and the loss of these cells is a hallmark of progressive kidney disease.

Characteristic histological features of crescentic glomerulonephritisinclude an irreversible loss of podocyte quiescence, aggravated endothelial injury and the development of cellular crescents all of which eventually lead to glomerular obsolescence. Cellular glomerular crescents are defined as two or more layers of proliferating cells in Bowman's space and are a hallmark of severe glomerular injury. The severity of the kidney failure and other clinical manifestations of glomerulonephritis (e.g. hypertension, oedema) correlate with the percentage of glomeruli that exhibit crescents on kidney biopsy. The proliferation of parietal epithelial cells and podocytes plays a key role in glomerular demolition by cellular crescent formation (10-12). Results from studies in human kidney biopsies and in a relevant mouse model have demonstrated that podocytes are deregulated in crescentic glomerulonephritis $(11,13)$; they lose their typical cell markers and switch to a proliferative and destructive phenotype before dying. Proliferation of these epithelial cells and infiltration of inflammatory cells leads to glomerular crescent formation and disruption of the specialized microvascular network in the glomerulus. This causes haematuria, albuminuria, and loss of renal function. During crescent formation in mouse models of crescentic glomerulonephritis, podocytes assume a migratory phenotype, attaching to the parietal basement membrane where they proliferate for a limited period of time (13-15). Recent data have confirmed that podocytes also contribute to crescent formation in man, although there is a great deal of heterogeneity in those affected suggesting that in some cases local regulatory mechanisms fail to maintain a quiescent podocyte phenotype $(12,16)$.

\section{Recent pathophysiological findings}

The recent findings that non-immune cells also play a role in crescent formation highlight the need to identify alternate and complementary therapeutic strategies. Thus, modulation of podocyte phenotype may help the glomerulus to withstand inflammatory stress and to prevent, or arrest, the destructive process of crescent formation. 


\subsection{Unlocking of podocyte quiescence at the root of glomerular demolition and crescentic glomerulonephritis}

In particular, we found de novo expression of the heparin-binding EGF-like growth factor (HB-EGF) in glomerular epithelial cells (podocytes and parietal cells) from both mice and humans with crescentic glomerulonephritis, eliciting epidermal growth factor receptor (EGFR) activation primarily in these cells, with subsequent glomerular lesions (17). In HB-EGF-deficient mice, EGFR activation in glomeruli is absent, and the course of crescentic glomerulonephritis induced by nephrotoxic antiglomerular basement membrane serum is improved. Autocrine HB-EGF induces a phenotypic switch in podocytes in vitro. Conditional deletion of the Egfr gene from podocytes of mice alleviates the severity of crescentic glomerulonephritis. Likewise, pharmacological blockade of EGFR also improves the course of crescentic glomerulonephritis, even when started 4 days after the experimental induction of the disease, when heavy albuminuria and glomerular inflammation are present. Although delineated in an experimental mouse model of crescentic glomerulonephritis, immunolabelling of human kidney biopsies suggests that the same pathway may be active in human disease (17). This indicates that the HB-EGF/EGFR pathway could play a pivotal role in crescentic glomerulonephritisand opens therapeutic perspectives $(18,19)$. In particular, development of selective anti-HB-EGF neutralising compounds should be an attractive option for therapy. Further studies will also be needed to evaluate how the HB-EGF/EGFR pathway is induced in disease and whether it displays additional pathophysiological actions.

Another important pathophysiological question is how does the HB-EGF/EGFR pathway trigger transient crescentic podocyte proliferation and dedifferentiation? We assumed that the deregulation of microribonucleic acid (miRNA) expression pattern may play a pleiotropic alteration of podocyte phenotype. Therefore, we carried out a miRNA profiling of freshly isolated glomeruli from mice after induction of crescentic glomerulonephritis with nephrotoxic antiglomerular basement membrane serum and also confirmed these data through miR profiling of laser microdissected glomeruli from random biopsies of individuals diagnosed with crescentic glomerulonephritis vs. non-crescentic proteinuric glomerular diseases (20). In particular, we focused on demonstrating the high miR-92a expression in podocytes in patients by combining fluorescent in situ hybridization and specific immunolabelling of podocytes. We went on by developing miRNA profiling of freshly sorted podocytes from nephritic and healthy mice. This model confirmed the human data and the accuracy of the experimental rapidly progressive glomerulonephritis.

We also demonstrated that induction of miR-92a in podocytes is a necessary critical event to foster glomerular damage and kidney failure as a new model of inducible podocyte selective miR-92a deficiency was found to be markedly tolerant to experimental crescentic glomerulonephritis. We hypothesized that abortive re-entry into the cell cycle of terminally differentiated post-mitotic 
podocytes upon immune-mediated stress is a dramatic and critical event leading to glomerular injury. Thus, we looked at changes in cell cycle regulators in podocytes in health and disease. Remarkably, analysis of miR-92a targets unravelled potent modulation of the chronic kidney disease inhibitor Cdkn1c/p57/Kip2 mRNA that we found to constitutively safeguards podocyte quiescence as we demonstrated by a knock-down experiment in primary podocytes. Another notable finding of our study is that EGFR and interleukin-6 (IL-6) drive signal transducer and activator of transcription 3 (STAT3) activation that is required to trigger miR-92a pathogenic expression. This may lead one to consider anti-STAT3 strategies as anti-miR-92a options. Meanwhile, from a therapeutic perspective, the identification of a molecular target that is as cell-specific as possible may be important to limit the undesired side effects associated with more upstream ubiquitous targets such as STAT3.

Finally, we also provided proof of principle that delayed anti-miR-92a strategy could display therapeutic actions on glomerular function and structure in a severe model of crescentic glomerulonephritis (20). Although this treatment showed an experimental therapeutic effect, it remains to be seen whether this holds true for human crescentic glomerulonephritis. Furthermore, although most of the pathophysiological actions of miR-92a were found in podocytes, involvement in parietal epithelial cells pathogenic activation is likely. It is also important to note that anti-miR-92a strategies would be expected to alleviate endothelial inflammation, cardiac ischemia and atherosclerosis, potentially important given the high risk of cardiovascular disease associated with crescentic glomerulonephritis $(9,24,21-25)$.

\subsection{A pivotal role for the peroxisomal proliferator activated receptor $\gamma$ in preventing glomerular epithelial cells pathogenic shift}

Cell proliferation and dedifferentiation involves a profound change in cell bioenergetics and chromatin remodelling. Peroxisomal proliferator activated receptor $\gamma$ (PPAR $\gamma$ ) belongs to the family of nuclear hormone receptors, which directly regulate the transcription of target genes. PPAR $\gamma$ endogenous ligands include free fatty acids and eicosanoids $(26,27)$. The regulatory role of this receptor on lipid metabolism and insulin sensitization is well established. PPAR $\gamma$ activation by specific agonists leads to growth inhibition, apoptosis, and differentiation of proliferative tumour cells. Podocytes constitutively express Ppar $\gamma \mathrm{mRNA}$ in vitro and this is reduced in models of glomerular inflammation (28). Furthermore, pioglitazone, a clinically used thiazolidinedione and pharmacological agonist of PPAR $\gamma$, increases both Ppar- $\gamma$ mRNA and activity in cultured podocytes (28). Systemic PPAR $\gamma$ stimulation is also effective in preventing podocyte injury in models of glomerular inflammation and rat models of diabetic nephropathy (29-34). There are likely multiple mechanisms explaining the renoprotection conferred by thiazolidinedione including a reduction in inflammation and fibrosis, suppression of the renin-angiotensin system and anti-apoptotic effects (35). It is also probable that these effects are mediated through a number of cell types including resident glomerular 
cells and immune cells. We next compared PPAR $\gamma$ expression in normal and crescentic glomeruli. We observed marked loss of PPAR $\gamma$ abundance and transcriptional activity in glomerular podocytes in nephrotoxic nephritis in mice and in kidneys from patients diagnosed with crescentic rapidly progressive glomerulonephritis.

Altogether, our findings indicate that inflammatory injury in small vessels vasculitides with crescentic glomerulonephritis propagates signals affecting the glomerular epithelial phenotype with profound alteration of the PPAR $\gamma$ expression, which coincides, with uncontrolled activation of the proinflammatory and profibrotic STAT3 cascade.

Thus, we carried out a study of the glomerular PPAR $\gamma$ pathway in acute, severe inflammatory crescentic glomerulonephritis induced by a nephrotoxic serum and evaluated the proof of principle that thiazolidinedione administration could treat this potentially lethal experimental disease (36). There have been a number of studies that have investigated the PPAR $\gamma$ system in relation to the kidney. One of the first of these from more than 10 years ago showed that preventive administration of a thiazolidinedione reduced proteinuria and crescent formation in a model of antiglomerular basement membrane disease in rats (37). This protective effect was attributed to an anti-inflammatory action of PPAR $\gamma$ in myeloid cells.

Meanwhile, given the strong constitutive expression of PPAR $\gamma$ in glomerular epithelial cells, we designed a podocyte-specific loss of function approach in a model of nephrotoxic serum-induced crescentic glomerulonephritis. Podocyte-specific abrogation of PPAR $\gamma$ did not alter the kidney development and physiology but exacerbated crescentic glomerulonephritis-related renal injury, illustrating the crucial local homeostatic role for this transcription factor. In this model, humoral and cellular immune responses were not targeted. These observations support PPAR $\gamma$ activation in podocytes as a potentially disease-limiting pathway in a severe form of extracapillary glomerulonephritis. Mirroring this loss of function approach, a gain of function approach - by means of PPAR $\gamma$ receptor activation - conferred similarly significant histopathological and functional glomerular protection (despite an untouched anti glomerular basement membrane humoral response). Importantly, from a clinical perspective, delayed administration ("therapeutic dosing") of a PPAR $\gamma$ receptor activator was as effective as the preventive dosing strategy.

Although it is considered that PPAR $\gamma$ agonism primarily influences the natural history of disease through anti-inflammatory actions on endothelial and myeloid cells (38-40), our data suggest an alternative pathway that focuses on the podocyte. Notably, PPAR $\gamma$ deficiency significantly accentuated peri-glomerular infiltrates of T cells and macrophages as well as Mcpl and Il6 mRNA abundance in the kidney cortex of nephritic mice. These two cytokines were used as measures of renal inflammation as they are involved in several diseases where crescentic injury is seen (41-51). It is 
somewhat surprising that the deletion of a single pathway (PPAR $\gamma$ ) in a single cell type (the podocyte) could promote such an impressive increase (approximately 30\%) in both $M c p-1$ and $I l-6$ mRNA levels, as well as adding to severe local damage but this goes to highlight the importance of the podocyte PPAR $\gamma$ system in this disease process. We cannot exclude PPAR $\gamma$-dependent paracrine effects of the diseased podocytes on surrounding inflammatory cells such as limitation of endogenous danger signals released by injured podocytes; a question that will require further studies. Interestingly, since pioglitazone treatment prevented proteinuria and the increased expression of transient receptor potential cation channel, subfamily $\mathrm{C}$, member 6 (TRPC6) in rats with adriamycin-induced nephropathy and since chromatin immunoprecipitation showed PPAR $\gamma$ binding to the TRPC6 promoter, we hypothesize that part of the cytoprotective effect of PPAR $\gamma$ in podocyte may involve limitation of potentially deleterious TRPC6 overactivity (52-54).

To address the question as to whether the beneficial effects of thiazolidinedione administration in experimental crescentic glomerulonephritis are mediated in part through actions on the podocyte, we treated podocyte-specific PPAR $\gamma$-deficient mice with a regimen that was effective in normal wild type mice. Surprisingly, pioglitazone administration was significantly less beneficial in these podocyte-specific PPAR $\gamma$-deficient mice compared to controls suggesting that a significant part of the beneficial action of pioglitazone administration is mediated through the podocyte PPAR $\gamma$ pathway (as well as complementary anti-inflammatory actions on immune cells) $(37,55)$. These findings highlight the important homeostatic mechanisms of podocytes in managing inflammatory stress. Furthermore, PPAR $\gamma$ was found to be a downstream effector of the nuclear factor (erythroid-derived 2)-like 2 (NRF2) pathway, unveiling the critical protective role of both NRF2 activity and PPAR $\gamma$ in inflammatory condition. We also provided proof of principle that delayed PPAR $\gamma$ agonism could display therapeutic actions on glomerular function and structure in a severe model of crescentic glomerulonephritis. Interestingly, pioglitazone is readily available for testing in a repurposing scheme, allowing for rapid initiation of future clinical trials. We expect that stimulation of PPAR $\gamma$ with repurposed pioglitazone and/or inhibition of the HB-EGF-miR92a cascade will bring original therapeutic effect by preventing podocytes death and dysfunction in addition to promoting antiinflammatory actions.

\section{Conclusion}

Our studies demonstrate the pivotal role of the local systems in maintaining podocyte survival and quiescence and orchestrating the global glomerular tolerance to a severe crescentic glomerulonephritis model. We hope that such approaches deciphering mechanisms of cellular adaptation that underlie kidney damage control in response to vasculitides and integrating both stress and damage responses will delineate novel complementary therapies in the future. 


\section{Disclosure}

The authors have nothing to disclose.

\section{Funding}

This work was supported by Institut national de santé et de la recherche médicale (Inserm) and research grants from l'Agence nationale de la recherche (ANR) of France (SWITCHES in Glomerular Diseases 2012) and from the European Research Council under the European Union's Seventh Framework Programme (FP7/2007-2013)/ERC grant agreement no. 107037) to P-L T.

\section{References}

1. Booth AD, Almond MK, Burns A, Ellis P, Gaskin G, Neild GH, et al. Outcome of ANCAassociated renal vasculitis: a 5-year retrospective study. Am J Kidney Dis 2003;41(4):776-84.

2. Schonermarck U, Gross WL, de Groot K. Treatment of ANCA-associated vasculitis. Nat Rev Nephrol 2014;10(1):25-36.

3. Guillevin L. Treatment of severe and/or refractory ANCA-associated vasculitis. Curr Rheumatol Rep 2014;16(8):430.

4. van Daalen EE, Rizzo R, Kronbichler A, Wolterbeek R, Bruijn JA, Jayne DR, et al. Effect of rituximab on malignancy risk in patients with ANCA-associated vasculitis. Ann Rheum Dis 2017 Jun;76(6):1064-9.

5. Wall N, Harper L. Complications of long-term therapy for ANCA-associated systemic vasculitis. Nat Rev Nephrol 2012;8(9):523-32.

6. Lode HM, Schmidt-Ioanas M. Vasculitis and infection: effects of immunosuppressive therapy. Clin Nephrol 2005;64(6):475-9.

7. Wallace ZS, Lu N, Unizony S, Stone JH, Choi HK. Improved survival in granulomatosis with polyangiitis: A general population-based study. Semin Arthritis Rheum 2016;45(4):483-9.

8. Heijl C, Mohammad AJ, Westman K, Hoglund P. Long-term patient survival in a Swedish population-based cohort of patients with ANCA-associated vasculitis. RMD Open. 2017;3(1):e000435.

9. Flossmann O, Berden A, de Groot K, Hagen C, Harper L, Heijl C, et al. Long-term patient survival in ANCA-associated vasculitis. Ann Rheum Dis 2011;70(3):488-94. 
10. Smeets B, Uhlig S, Fuss A, Mooren F, Wetzels JF, Floege J, et al. Tracing the origin of glomerular extracapillary lesions from parietal epithelial cells. J Am Soc Nephrol 2009;20(12):260415.

11. Bariety J, Bruneval P, Meyrier A, Mandet C, Hill G, Jacquot C. Podocyte involvement in human immune crescentic glomerulonephritis. Kidney Int 2005;68(3):1109-19.

12. Thorner PS, Ho M, Eremina V, Sado Y, Quaggin S. Podocytes contribute to the formation of glomerular crescents. J Am Soc Nephrol 2008;19(3):495-502.

13. Moeller MJ, Soofi A, Hartmann I, Le Hir M, Wiggins R, Kriz W, et al. Podocytes populate cellular crescents in a murine model of inflammatory glomerulonephritis. J Am Soc Nephrol 2004;15(1):61-7.

14. Besse-Eschmann V, Le Hir M, Endlich N, Endlich K. Alteration of podocytes in a murine model of crescentic glomerulonephritis. Histochem Cell Biol 2004;122(2):139-49.

15. Le Hir M, Keller C, Eschmann V, Hahnel B, Hosser H, Kriz W. Podocyte bridges between the tuft and Bowman's capsule: an early event in experimental crescentic glomerulonephritis. J Am Soc Nephrol 2001;12(10):2060-71.

16. Bariety J, Mandet C, Hill GS, Bruneval P. Parietal podocytes in normal human glomeruli. J Am Soc Nephrol 2006;17(10):2770-80.

17. Bollee G, Flamant M, Schordan S, Fligny C, Rumpel E, Milon M, et al. Epidermal growth factor receptor promotes glomerular injury and renal failure in rapidly progressive crescentic glomerulonephritis. Nat Med 2011;17(10):1242-50.

18. Flamant M, Bollee G, Henique C, Tharaux PL. Epidermal growth factor: a new therapeutic target in glomerular disease. Nephrol Dial Transplant 2012;27(4):1297-304.

19. Harris R. EGFR signaling in podocytes at the root of glomerular disease. Nat Med 2011;17(10):1188-9.

20. Henique C, Bollee G, Loyer X, Grahammer F, Dhaun N, Camus M, et al. Genetic and pharmacological inhibition of microRNA-92a maintains podocyte cell cycle quiescence and limits crescentic glomerulonephritis. Nat Comm 2017;8(1):1829.

21. Daniel JM, Penzkofer D, Teske R, Dutzmann J, Koch A, Bielenberg W, et al. Inhibition of miR-92a improves re-endothelialization and prevents neointima formation following vascular injury. Cardiovasc Res 2014;103(4):564-72. 
22. Hinkel R, Penzkofer D, Zuhlke S, Fischer A, Husada W, Xu QF, et al. Inhibition of microRNA-92a protects against ischemia/reperfusion injury in a large-animal model. Circulation 2013 Sep 03;128(10):1066-75.

23. Loyer X, Potteaux S, Vion AC, Guerin CL, Boulkroun S, Rautou PE, et al. Inhibition of microRNA-92a prevents endothelial dysfunction and atherosclerosis in mice. Circ Res 2014;114(3):434-43.

24. Morgan MD, Turnbull J, Selamet U, Kaur-Hayer M, Nightingale P, Ferro CJ, et al. Increased incidence of cardiovascular events in patients with antineutrophil cytoplasmic antibody-associated vasculitides: a matched-pair cohort study. Arthritis Rheum 2009;60(11):3493-500.

25. Roman MJ, Shanker BA, Davis A, Lockshin MD, Sammaritano L, Simantov R, et al. Prevalence and correlates of accelerated atherosclerosis in systemic lupus erythematosus. N Engl J Med 2003;349(25):2399-406.

26. Heikkinen S, Auwerx J, Argmann CA. PPARgamma in human and mouse physiology. Biochim Biophys Acta 2007;1771(8):999-1013.

27. Ahmadian M, Suh JM, Hah N, Liddle C, Atkins AR, Downes M, et al. PPARgamma signaling and metabolism: the good, the bad and the future. Nat Med 2013;19(5):557-66.

28. Kanjanabuch T, Ma LJ, Chen J, Pozzi A, Guan Y, Mundel P, et al. PPAR-gamma agonist protects podocytes from injury. Kidney Int 2007;71(12):1232-9.

29. Zuo Y, Yang HC, Potthoff SA, Najafian B, Kon V, Ma LJ, et al. Protective effects of PPARgamma agonist in acute nephrotic syndrome. Nephrol Dial Transplant 2012;27(1):174-81.

30. Ma LJ, Marcantoni C, Linton MF, Fazio S, Fogo AB. Peroxisome proliferator-activated receptor-gamma agonist troglitazone protects against nondiabetic glomerulosclerosis in rats. Kidney Int 2001;59(5):1899-910.

31. Buckingham RE, Al-Barazanji KA, Toseland CD, Slaughter M, Connor SC, West A, et al. Peroxisome proliferator-activated receptor-gamma agonist, rosiglitazone, protects against nephropathy and pancreatic islet abnormalities in Zucker fatty rats. Diabetes 1998;47(8):1326-34.

32. Yang HC, Ma LJ, Ma J, Fogo AB. Peroxisome proliferator-activated receptor-gamma agonist is protective in podocyte injury-associated sclerosis. Kidney Int 2006;69(10):1756-64.

33. Cha DR, Zhang X, Zhang Y, Wu J, Su D, Han JY, et al. Peroxisome proliferator activated receptor alpha/gamma dual agonist tesaglitazar attenuates diabetic nephropathy in $\mathrm{db} / \mathrm{db}$ mice. Diabetes 2007;56(8):2036-45. 
34. Calkin AC, Giunti S, Jandeleit-Dahm KA, Allen TJ, Cooper ME, Thomas MC. PPAR-alpha and -gamma agonists attenuate diabetic kidney disease in the apolipoprotein E knockout mouse. Nephrol Dial Transplant 2006;21(9):2399-405.

35. Yang J, Zhou Y, Guan Y. PPARgamma as a therapeutic target in diabetic nephropathy and other renal diseases. Curr Opin Nephrol Hypertens 2012;21(1):97-105.

36. Henique C, Bollee G, Lenoir O, Dhaun N, Camus M, Chipont A, et al. Nuclear factor erythroid 2-related factor 2 drives podocyte-specific expression of peroxisome proliferator-activated receptor gamma essential for resistance to crescentic GN. J Am Soc Nephrol 2016;27(1):172-88.

37. Haraguchi K, Shimura H, Onaya T. Suppression of experimental crescentic glomerulonephritis by peroxisome proliferator-activated receptor (PPAR)gamma activators. Clin Exp Nephrol $2003 ; 7(1): 27-32$.

38. Straus DS, Glass CK. Anti-inflammatory actions of PPAR ligands: new insights on cellular and molecular mechanisms. Trends Immunol 2007;28(12):551-8.

39. Bouhlel MA, Derudas B, Rigamonti E, Dievart R, Brozek J, Haulon S, et al. PPARgamma activation primes human monocytes into alternative M2 macrophages with anti-inflammatory properties. Cell Metab 2007;6(2):137-43.

40. Chinetti G, Griglio S, Antonucci M, Torra IP, Delerive P, Majd Z, et al. Activation of proliferator-activated receptors alpha and gamma induces apoptosis of human monocyte-derived macrophages. J Biol Chem 1998;273(40):25573-80.

41. Herrera-Esparza R, Barbosa-Cisneros O, Villalobos-Hurtado R, Avalos-Diaz E. Renal expression of IL-6 and TNFalpha genes in lupus nephritis. Lupus 1998;7(3):154-8.

42. Ryffel B, Car BD, Gunn H, Roman D, Hiestand P, Mihatsch MJ. Interleukin-6 exacerbates glomerulonephritis in (NZB x NZW)F1 mice. Am J Pathol 1994;144(5):927-37

43. Kiberd BA. Interleukin-6 receptor blockage ameliorates murine lupus nephritis. J Am Soc Nephrol 1993;4(1):58-61.

44. Liang B, Gardner DB, Griswold DE, Bugelski PJ, Song XY. Anti-interleukin-6 monoclonal antibody inhibits autoimmune responses in a murine model of systemic lupus erythematosus. Immunology 2006;119(3):296-305.

45. Tackey E, Lipsky PE, Illei GG. Rationale for interleukin-6 blockade in systemic lupus erythematosus. Lupus 2004;13(5):339-43. 
46. Sumida K, Ubara Y, Suwabe T, Hayami N, Hiramatsu R, Hasegawa E, et al. Complete remission of myeloperoxidase-antineutrophil cytoplasmic antibody-associated crescentic glomerulonephritis complicated with rheumatoid arthritis using a humanized anti-interleukin 6 receptor antibody. Rheumatology 2011;50(10):1928-30.

47. Iijima T, Suwabe T, Sumida K, Hayami N, Hiramatsu R, Hasegawa E, et al. Tocilizumab improves systemic rheumatoid vasculitis with necrotizing crescentic glomerulonephritis. Modern Rheumatol 2015;25(1):138-42.

48. Barbado J, Martin D, Vega L, Almansa R, Goncalves L, Nocito M, et al. MCP-1 in urine as biomarker of disease activity in systemic lupus erythematosus. Cytokine 2012;60(2):583-6.

49. Lloyd CM, Minto AW, Dorf ME, Proudfoot A, Wells TN, Salant DJ, et al. RANTES and monocyte chemoattractant protein-1 (MCP-1) play an important role in the inflammatory phase of crescentic nephritis, but only MCP-1 is involved in crescent formation and interstitial fibrosis. J Exp Med 1997;185(7):1371-80.

50. Lloyd CM, Dorf ME, Proudfoot A, Salant DJ, Gutierrez-Ramos JC. Role of MCP-1 and RANTES in inflammation and progression to fibrosis during murine crescentic nephritis. J Leukoc Biol 1997;62(5):676-80.

51. Hasegawa H, Kohno M, Sasaki M, Inoue A, Ito MR, Terada M, et al. Antagonist of monocyte chemoattractant protein 1 ameliorates the initiation and progression of lupus nephritis and renal vasculitis in MRL/lpr mice. Arthritis Rheum 2003;48(9):2555-66.

52. Sonneveld R, Hoenderop JG, Isidori AM, Henique C, Dijkman HB, Berden JH, et al. Sildenafil prevents podocyte injury via PPAR-gamma-mediated TRPC6 inhibition. J Am Soc Nephrol 2017;28(5):1491-505.

53. Winn MP, Conlon PJ, Lynn KL, Farrington MK, Creazzo T, Hawkins AF, et al. A mutation in the TRPC6 cation channel causes familial focal segmental glomerulosclerosis. Science 2005;308(5729):1801-4.

54. Ilatovskaya DV, Staruschenko A. TRPC6 channel as an emerging determinant of the podocyte injury susceptibility in kidney diseases. Am J Physiol Renal Physiol 2015;309(5):F393-7.

55. Chafin C, Muse S, Hontecillas R, Bassaganya-Riera J, Caudell DL, Shimp SK, 3rd, et al. Deletion of PPAR-gamma in immune cells enhances susceptibility to antiglomerular basement membrane disease. J Inflamm Res 2010;3:127-34. 